\title{
$\begin{array}{ll}\text { Research Square } & \text { Preprints are preliminary reports that have not undergone peer review. } \\ \text { They should not be considered conclusive, used to inform clinical practice, }\end{array}$ or referenced by the media as validated information.
}

\section{The Impact of Long-COVID on Functioning - Results from a Community Survey in Patients After Mild and Moderate SARS-CoV-2-Infection in Germany}

Christina Lemhöfer ( $\sim$ christina.lemhoefer@med.uni-jena.de )

Jena University Hospital: Universitatsklinikum Jena

Christian Sturm

Hannover Medical School: Medizinische Hochschule Hannover

Dana Loudovici-Krug

Jena University Hospital: Universitatsklinikum Jena

Norman Best

Jena University Hospital: Universitatsklinikum Jena

Christoph Gutenbrunner

Hannover Medical School: Medizinische Hochschule Hannover

\section{Research}

Keywords: Long-COVID, mild and moderate COVID-19, impact on functioning, quality of life

Posted Date: April 13th, 2021

DOI: https://doi.org/10.21203/rs.3.rs-383483/v1

License: (c) (1) This work is licensed under a Creative Commons Attribution 4.0 International License.

Read Full License 


\section{Abstract}

\section{Background}

In COVID-19 survivors a relatively high number of long-term symptoms have been observed. Besides impact on quality of life, these symptom (now called long-COVID) may have an impact on functioning and my hinder affected people to participate in social life. However, little is known if and to what extent patients with mild and moderate COVID-19 who did not need hospitalization or intensive care develop such a syndrome.

\section{Methods}

A cross-sectional study in 1027 patients with mild or moderate COVID-19 has been performed in two communities in Bavaria, Germany. The Rehabilitation-Needs-Survey (RehabNeS) that includes Short Form 36 health questionnaire (SF-36) on health-related quality of life, was performed. Descriptive statistics were calculated.

Results

$97.5 \%$ of patients reported one symptom in infection phase such as fatigue, respiratory problems, limitations of the sense of taste and smell, as well as fear and anxiety and other symptoms. In this phase $84.1 \%$ of participants experienced activity limitations and participation restrictions such as carrying out daily routine, handling stress, getting household tasks done, care/support for others, and relaxing and leisure.

$61.9 \%$ of participants reported persisting symptoms after more than 3 months after infection. These were among others fatigue, sleep disturbances, respiratory problems pain, fears and anxiety, and restrictions in movement. $49 \%$ of the participants reported on activity limitations and participation restrictions. Predominately these were handling stress, carrying out daily routine, looking after one's health, relaxing and leisure activities as well as doing house work.

The impact on quality of life and vocational performance were rather low.

Conclusion

The results show that long-term symptoms after mild and moderate COVID-19 are common and lead to limitations of activities and participation. However, it seems that in most cases they are not very severe and do not lead to frequent or severe issues with quality of live or work ability.

\section{Introduction And Background}

Corona Virus infections are known to lead to Severe Acute Respiratory Syndromes $(S A R S)(1,2)$. When a novel Corona Virus has been detected in Wuhan, China, severe courses of the disease leading to the need 
of intensive care, artificial respiration or Extra-Corporal Membrane Oxygenation (ECMO) have been observed (3). More than one year after the first detection of the Severe Acute Respiratory Syndrome Corona Virus Type 2 (SARS-CoV-2) more data about the severity and course of the Infection is available. According to epidemiological data the Corona Virus Disease first observed in 2019 (COVID-19) leads to severe airway disease in around $15 \%(3,4)$, and around $5 \%$ develop critical illness mostly requiring artificial ventilation (4). Around $80 \%$ of patients are asymptomatic or develop only mild or moderate symptoms (5). Worldwide around $2 \%$ of infected patients died from COVID-Infections or related complications (6), however, reported death rates due to methodological differences vary within wide ranges. Risk factors for severe courses are old age, metabolic and renal disease, cardiovascular diseases, and obesity $(7,8)$.

Around 6 months after the description of COVID-19 Chinese researchers published observations that even weeks or months after the acute lung disease long-term functional symptoms can be observed in a relatively high number of COVID-19 survivors (9). Some of these symptoms can be seen as "non-specific", other can be interpreted result from infection or immune response in other organs or organ system such as kidney, cardiovascular system as well as brain and the peripheral nervous system (9).Frequently observed symptoms are fatigue, headache, dyspnea and anosmia $(10,11)$. Of course, pulmonary symptoms like coughing and dyspnea and reduced cardiopulmonary performance are observed too in patients with the so-called post-COVID-Syndrome, frequently also called Long-COVID (12).

Besides impact on quality of life $(Q o L)$, long-COVID has an impact on functioning and my hinder effected people to participate in social life. This may include unfitness for work with impact on personal income and society productivity. For example, people with severe fatigue will not be able to work with machines, drive vehicles of do office work. If alterations of smell and taste occur work in restaurants may not be possible any more, and alterations of motor functions may be a barrier for many jobs in the field of trade. These examples show that Long-COVID may be an indication for rehabilitation interventions (13). This includes acute, post-acute and long-term rehabilitation (14-16).

Little is known if and to what extent patients with mild and moderate COVID-19 who did not need hospitalization or intensive care suffer from Post-COVID and how much quality of life is affected. From the point of view of rehabilitation, an estimation of rehabilitation needs is of interest. In order to answer these questions a community survey in patients after mild and moderate SARS-CoV-2-Infection in Germany have been performed.

\section{Material And Methods}

For this cross-sectional study, a new written survey instrument was developed in a cooperation be-tween the University Hospital Jena (Institute for Physiotherapy), the Hannover Medical School (Department of Rehabilitation Medicine) and the last author in her work for the Association of Statutory Health Insurance Physicians of Bavaria; a new written survey instrument was developed in early summer 2020. The Rehabilitation-Needs-Survey (RehabNeS) includes, in addition to the established Short Form 36 health 
questionnaire (SF-36) on health-related quality of life, a newly created questionnaire, the RehabilitationNeeds-Questionnaire (RehabNeQ) with eleven dimensions and a total of 57 items that evaluates the rehabilitation needs of COVID-19 sufferers and additionally asks about satisfaction with the actors of the health care system and treatment in the context of infection (17).

After the positive vote of the ethics committee of the medical faculty of the Friedrich Schiller University Jena (registration number 2020-1834-Bef), contact was made with two Bavarian community public health departments The contents of the questionnaire and the aim of the study were explained and a cooperation was agreed upon. Subsequently, a selection of the positively tested SARS-CoV-2 infected persons was carried out by the public health departments by the cut-off date 18.07.2020. Patients under 18 years of age as well as residents of dementia homes were excluded. The study center then sent 1027 prepaid envelopes containing the questionnaires to the health departments. The local staff addressed and mailed the envelopes. There was no transmission of personal data to the study center. Additional respondents were included by direct approach in the course of medical care by the first author after informed consent. Patients did not receive a reminder letter. The costs of the material resources were covered by the participating universities.

The questionnaires were returned anonymized in a prepaid envelope to the Institute of Physiotherapy of Jena University Hospital. The data are refurbished in a descriptive way regarding the absolute and percentage frequency. The patients were asked to specify their health problems on a scale of 1 to 5 , where 1 means no problem and 5 means an extreme problem. With regard to the analysis presented here, the specifications were summarized as 2 to 5 . Furthermore they should state if the problem still exists. The same questions were asked referring to the patients' activity and participation. Moreover, the SF-36 was evaluated using the official scoring system (18). The calculated values are related to the results of the German norm sample.

\section{Results}

Sample characteristics. For evaluation 365 completely filled-in questionnaires could be used. 216 (59.2\%) of respondents were female, $148(40.5 \%)$ were male. One respondent did not specify gender. The mean age of participants were $49.8(+/-16.9)$ years and $82 \%$ were within the age range of $18-64$ where in Germany remunerative employment (or job training) is common. The marital status, education level and living situation were similar to German average population. The majority of participants (93.7\%) stated that the acute infection has been occurring more than three months before the survey.

Symptoms and Activity and Participation during the infection phase. $97.5 \%$ of patients reported one symptom and $84 \%$ experienced activity limitations and participation restrictions in infection phase. The participants reported most frequently experienced (Fig. 1a): Lassitude/fatigue (81.1\%), respiratory problems $(60.5 \%)$, limitations of the sense of taste (60.5\%) and smell (68.6\%), Fears and anxiety (55.3\%), sleep problems $(53.7 \%)$, bowel dysfunction $(44.9 \%)$, pain $(40.5 \%)$, circulatory problems or disorders 
(38.4\%), restrictions on movement (36.9\%), muscular problems (25.8\%), and bladder dysfunction (18.4\%). $69,9 \%$ of the subjects experienced shortness of breath during physical exertion resp. activity.

With regard to activities and participation during the infection phase in the following dimensions problems were reported (Fig. 1b): "daily routine" (67,1\%), "handling stress" (62.5\%), "getting household tasks done" (49.3\%) and "care/support for others" (49.3\%), "relaxing, having pleasure" (48.2\%), "looking after your health" (46.9\%), " having intimate relationships" (42.5\%), "interaction with people" (40.0\%), "getting where you want to go" (32.7\%), "using hands and fingers" (28\%), "use of public transportation" (25.5\%), and "use of private transportation" (25.4\%)

\section{Symptoms and Activity and Participation at the time of survey}

Summing up the number of symptoms, 226 participants (61.9\%) of the total sample report long-term symptoms. In 48 cases one (13.2\%), in 33 cases two (9.0\%), in 33 cases three (9.0\%), and in 112 cases four or more symptoms (30.7\%) were reported (Fig. 2a).

$38.1 \%$ of cases did not report any long-term symptoms. The distribution of persisting symptoms was as follows Lassitude/fatigue (37.5\%), sleep problems (30.1\%), respiratory problems (26.0\%), pain (26.0\%), Fears and anxiety $(24.9 \%)$, restrictions on movement (18.4\%), alterations of smell (17.3\%) an taste (16.2\%), cardiovascular problems (15.1\%), bowel dysfunction (14.0\%), muscular problems $(12.0 \%)$, and bladder dysfunction (7.9\%).

Summing up the number of reported problems in activity and participation in the long-term phase, 179 participants $(49.0 \%)$ of the total sample report long-term activity limitations and participation restrictions. In 56 cases one (15.3\%), in 23 cases two (6.3\%), in 24 cases $3(6.6 \%)$ and in 76 cases four or more (20.8\%) problems were reported (Fig. 2b). The number of persisting problems after more than three months were: "handling stress" (23.8\%), "daily routine" (18.1\%), "looking after your health" (15.3\%), "relaxing, having pleasure" (15.1\%), "getting household tasks done" (12.9\%), "care/support for others" (12.1\%), "having intimate relationships" (11.8\%), "using hands and fingers" (9.6\%), "interaction with others" (7.7\%), "use of public transportation" (5.8\%), "getting where you want to go" (5.5\%), and "use of private transportation" (2.7\%). According to physical exertion, still $37.7 \%$ stated shortness of breath meanwhile.

Quality of Life. Overall score of quality of life in most cases was very good (25.6\%) or good (52.6\%). Average quality of life was scored in $17.5 \%$. Bad $(3.9 \%)$ or very bad $(0.3 \%)$ QoL was stated in only a few cases. The mean values in SF-36 questionnaire in the physical sum score was with 49.2 points in the range of normal population (48.4 points) (Fig. 3a). Mental sum score was slightly reduced (45.7 vs. 50.9 in normal population). Reduced average scores were found in particular in the dimensions "role physical" (70.8 vs. 82.4), "vitality" (54.6 vs. 60.0), social function" (74.5 vs. 86.4), "role emotional" (69.5 vs. 89.7), 
and "mental health" (69.2 vs. 72.5). In the subgroup of participants in between 18 and 64 years of age that numbers did not differ much (Table 1 ).

Table 1

Results of SF-36 in participants in working age (18-64 years)

\begin{tabular}{|lcccccccccc|}
\hline & PF & RP & BP & GH & VT & SF & RE & MH & PCS & MCS \\
\hline $\begin{array}{l}\text { Under 65 years (n } \\
=291)\end{array}$ & 86.7 & 76.8 & 78.2 & 68.7 & 55.6 & 76.5 & 74.5 & 70.4 & 50.8 & 46.3 \\
\hline $\begin{array}{l}\text { In total } \\
(\mathrm{n}=365)\end{array}$ & 82.4 & 70.8 & 76.3 & 66.5 & 54.6 & 74.5 & 69.5 & 69.2 & 49.2 & 45.7 \\
\hline $\begin{array}{l}\text { PF = physical function, RP = role Physical, BP = bodily Pain, GH = general helath, V = vitality, SF = social } \\
\text { function, RE = role emotional, MH = mental helath, PCS = physical component Scale, MCS = mental } \\
\text { component scale }\end{array}$
\end{tabular}

Rehabilitation need/unfitness for work. From the 291 participants in the age of 10-64 $(n=291) 255$ $(87.6 \%)$ of participants declared to be in remunerative employment, $5(1.7 \%)$ were seeking for a job and $21(7.7 \%)$ did not have an remunerative employment or received pension payment. Only $2.4 \%$ of those who had a job have been classified by the doctors being "unfit for work" (according to German social regulations).

\section{Discussion}

Overall, the results show that patients three months after mild and moderate COVID-19 show at least one symptom in $61,9 \%$ of cases. As these symptoms are addressed as related to the SARS-CoV-2 infection they can be addressed as Long-COVID $(11,19-21)$. This percentage is similar to findings by Jacobsen et al. (22) but clearly lower as been reported by Huang et al. (9). The reason for this difference may be that Huang et al. had a higher number of severe and critical cases in their sample. Patients with longer artificial respiration periods and Intensive care treatment may develop SARS-CoV-2 independent symptoms, as described as Post-Intensive Care-Syndrome (PICS) (23).

The symptom profile from our study demonstrates that - besides effects symptoms related to pneumonia - non-specific symptom are dominating such as fatigue, mental symptoms and pain. Additionally a number of symptoms may be related to alterations of the nervous system. This is congruent with findings from Wang et al. (24) and Lenzen-Schulte (21). This profile shows similarities with the long-term symptoms of other severe diseases like cancer or auto-immune syndromes (25). One explanation for these similarities may be that in COVID-19 after the primary lung infection as second phase of the disease has been observed. This symptoms of the phase can be explained by a hyperimmune response (26). However the mechanisms of Long-COVID need to be elucidated further.

Date on the impact of Long-COVID on functioning are scarce. An Italian study described that about half of the Post-COVID-19 patients had severe impairments in physical functioning and activities of daily 
living at hospital discharge (27). Jacobson et al. (22) showed that $46 \%$ of the mildly affected patients and $73 \%$ of the hospitalized patients had an activity impairment due to the disease 3-4 months after their initial COVID-19 diagnosis. This is consistent with our findings that $49 \%$ of respondents reported at least one limitation of activities and/or restrictions in participation.

However, the mean levels of quality of life domains seems to be relatively close to the normal population. This shows that mild and moderate courses of the SARS-CoV-2 infection causes much less long-term alterations as compared with severe and critical causes as well as other SARS diseases (9). Nevertheless, the relatively young population of our survey show some conspicuous results. At the level of scales, SF36 showed deficits of physical role, and slightly stronger in the scales of social function and emotional role. This may be related to findings that mental disorders are frequently seen in patients after SARSCoV-2 infection $(11,28)$. The effects described are not as significant when the 18-64 age group is considered separately. However, the strongest deviations compared to the normal population also exist in the scales emotional role and social function. The long-term impact on activity and participation concerns only the minority of participants ranging from around 3 to 24 percent. The profile of alterations seems to relate to the above mentioned non-specific symptoms and mental problem and handling stress (24\%) and managing daily demands (18\%) are dominating. Another result has not been reported yet are problems with intimate relationships (12\%).

The need for rehabilitation was not explicitly in the focus of the used questionnaire. However, the observed symptoms, activity limitations and participation restrictions suggest that a relevant need for rehabilitation is existent in the population of mild and severe SARS-CoV-2 infections. With regard to the symptom level the percentages of persons who need rehabilitation intervention can be estimated to 15$35 \%$. The detected impact on functioning results in a relatively lower percentage in need for rehabilitation (estimated around 10-25\%). Unfitness to work also occurs in the population of the survey, however their percentage is relatively low (around 5\%). This can be seen as a sign that the people after mild and moderate COVID-19 may compensate the remaining problems relatively good. From the point of view of work performance the percentage of people in need of rehabilitation may only be around $5 \%$.

The main limitation of the study is that it has been performed without a control group with matched samples. Due to the urgency and organizational problem it was not possible to recruit an appropriate control group. Another limitation is that we could not differentiate severity of the SARS-COV-2 infection because we had to use an anonymous data sampling approach. Also no detailed information about the possible phenomenon of presentism at the work place. It also can be discussed if a more sensitive questionnaire of life questionnaire could have made it possible to derive more differentiated profiles.

In conclusion, this retrospective questionnaire-bases survey show that patients with mild and moderate SARS-CoV-2 infection in the early_phase of the disease the most frequent symptoms were fatigue, respiratory problems, limitations of the sense of taste and smell, fears and anxiety together with a broad range of other symptoms. In this phase, $84 \%$ of participants reported limitations of activity and participation, consisting mostly of carrying out daily routine, handling stress, doing household taking care 
for or support others as well as problems with leisure activities. At the time of survey that was around 3 months after the acute infection, $61.9 \%$ of participants reported at least one remaining symptoms such as fatigue, sleep disturbances, respiratory problems, pain, fears and anxiety and movement restrictions. Around $1 / 2$ of the patients (49\%) reported at least one activity limitations and participation restrictions such as handling stress, carrying out daily routine, looking after own health, relaxing and leisure activities carrying out house work.

Despite of these high numbers of symptoms and activity and participation the overall quality of life, as analyzed with the SF-36 Health Survey questionnaire sowed relatively small reduction of mean values as compared to the German normal sample. This is also the case in the population in working age. Only a small group of patients with mild and moderate COVID-19 experiences long-term unfitness for work.

These results show that long-term symptoms after mild and moderate COVID-19 are common and lead to limitations of activities and participation. However, it seem that in most cases they are not very severe and do not lead to frequent or severe issues with quality of live or work ability.

\section{Declarations}

\section{Ethics approval and consent to participate}

positive vote of the ethics committee of the medical faculty of the Friedrich Schiller University Jena (registration number 2020-1834-Bef)

\section{Consent for publication}

'Not applicable

\section{Availability of data and materials}

The datasets used and analysed during the current study are available from the corresponding author on reasonable request

\section{Competing interests}

The authors declare that they have no competing interests

\section{Funding}

Not applicable

\section{Authors' contributions}

CS, CL and BN developed Survey Instrument, CS and NB were responsible for conducting the survey, DLK analyzed and interpreted the data, and CG and CL was a major contributor in writing the manuscript. All authors read and approved the final manuscript. 
Acknowledgements

Not applicable

\section{References}

1. Di Maria E, Latini A, Borgiani P, Novelli G. Genetic variants of the human host influencing the coronavirus-associated phenotypes (SARS, MERS and COVID-19): rapid systematic review and field synopsis. Hum Genomics 2020; 14(1):30.

2. Xie L, Liu Y, Xiao Y, Tian Q, Fan B, Zhao H et al. Follow-up study on pulmonary function and lung radiographic changes in rehabilitating severe acute respiratory syndrome patients after discharge. Chest 2005; 127(6):2119-24.

3. Ma X, Liang M, Ding M, Liu W, Ma H, Zhou X et al. Extracorporeal Membrane Oxygenation (ECMO) in Critically III Patients with Coronavirus Disease 2019 (COVID-19) Pneumonia and Acute Respiratory Distress Syndrome (ARDS). Med Sci Monit 2020; 26:e925364.

4. Wu Z, McGoogan JM. Characteristics of and Important Lessons From the Coronavirus Disease 2019 (COVID-19) Outbreak in China: Summary of a Report of 72314 Cases From the Chinese Center for Disease Control and Prevention. JAMA 2020; 323(13):1239-42.

5. Buitrago-Garcia D, Egli-Gany D, Counotte MJ, Hossmann S, Imeri H, Ipekci AM et al. Occurrence and transmission potential of asymptomatic and presymptomatic SARS-CoV-2 infections: A living systematic review and meta-analysis. PLoS Med 2020; 17(9):e1003346.

6. Dong E, Du H, Gardner L. An interactive web-based dashboard to track COVID-19 in real time. The Lancet Infectious Diseases 2020; 20(5):533-4.

7. Fathi M, Vakili K, Sayehmiri F, Mohamadkhani A, Hajiesmaeili M, Rezaei-Tavirani M et al. The prognostic value of comorbidity for the severity of COVID-19: A systematic review and meta-analysis study. PLoS One 2021; 16(2):e0246190.

8. Mudatsir M, Fajar JK, Wulandari L, Soegiarto G, Ilmawan M, Purnamasari Y et al. Predictors of COVID-19 severity: a systematic review and meta-analysis. F1000Res 2020; 9:1107.

9. Huang C, Huang L, Wang Y, Li X, Ren L, Gu X et al. 6-month consequences of COVID-19 in patients discharged from hospital: a cohort study. Lancet 2021; 397(10270):220-32.

10. Sudre CH, Murray B, Varsavsky T, Graham MS, Penfold RS, Bowyer RC et al. Attributes and predictors of Long-COVID: analysis of COVID cases and their symptoms collected by the Covid Symptoms Study App; 2020.

11. Townsend L, Dyer AH, Jones K, Dunne J, Mooney A, Gaffney F et al. Persistent fatigue following SARS-CoV-2 infection is common and independent of severity of initial infection. PLoS One 2020; 15(11):e0240784.

12. Leung TYM, Chan AYL, Chan EW, Chan VKY, Chui CSL, Cowling BJ et al. Short- and potential longterm adverse health outcomes of COVID-19: a rapid review. Emerg Microbes Infect 2020; 9(1):21909. 
13. Barker-Davies RM, O'Sullivan O, Senaratne KPP, Baker P, Cranley M, Dharm-Datta S et al. The Stanford Hall consensus statement for post-COVID-19 rehabilitation. Br J Sports Med 2020; 54(16):949-59.

14. Liebl ME, Gutenbrunner C, Glaesener JJ, Schwarzkopf S, Best N, Lichti G et al. Frühe Rehabilitation bei COVID-19 - Best Practice Empfehlungen für die frühe Rehabilitation von Patient/innen mit COVID-19. Phys Rehab Kur Med 2020; 30(03):129-34.

15. Gutenbrunner C, Stokes EK, Dreinhöfer K, Monsbakken J, Clarke S, Côté P et al. Why Rehabilitation must have priority during and after the COVID-19-pandemic: A position statement of the Global Rehabilitation Alliance. J Rehabil Med 2020; 52(7):jrm00081.

16. Simpson R, Robinson L. Rehabilitation After Critical Illness in People With COVID-19 Infection. Am J Phys Med Rehabil 2020; 99(6):470-4.

17. Lemhöfer C, Gutenbrunner C, Best N, Loudovici-Krug D, Schiller J, Bökel A et al. Assessment of rehabilitation needs in patients during and after COVID-19 - development of the COVID-19Rehabilitation Needs Survey (C19-RehabNeS). J Rehabil Med 2021.

18. Morfeld M, Bullinger M, Kirchberger I. Zitieren Morfeld, Matthias, Monika Bullinger, and Inge Kirchberger. Fragebogen zum Gesundheitszustand: SF-36; deutsche Version des Short form-36 health survey. Hogrefe; 2011.

19. Salehi S, Reddy S, Gholamrezanezhad A. Long-term Pulmonary Consequences of Coronavirus Disease 2019 (COVID-19): What We Know and What to Expect. J Thorac Imaging 2020.

20. Dasgupta A, Kalhan A, Kalra S. Long term complications and rehabilitation of COVID-19 patients. J Pak Med Assoc 2020; 70(Suppl 3)(5):S131-S135.

21. Lenzen-Schulte $m$. Long COVID: Der lange Schatten von COVID-19. Dtsch Arztebl International 2020; 117(49):A-2416. Available from: URL: https://www.aerzteblatt.de/int/article.asp?id=217002.

22. Jacobson KB, Rao M, Bonilla H, Subramanian A, Hack I, Madrigal M et al. Patients with uncomplicated COVID-19 have long-term persistent symptoms and functional impairment similar to patients with severe COVID-19: a cautionary tale during a global pandemic. Clin Infect Dis 2021.

23. Flash MJ, Johnson SF, Nguemeni Tiako MJ, Tan-McGrory A, Betancourt JR, Lamas DJ et al. Disparities in Post-Intensive Care Syndrome During the COVID-19 Pandemic: Challenges and Solutions. NEJM Catal Innov Care Deliv 2020.

24. Wang F, Kream RM, Stefano GB. Long-Term Respiratory and Neurological Sequelae of COVID-19. Med Sci Monit 2020; 26:e928996.

25. Gosain R, Miller K. Symptoms and symptom management in long-term cancer survivors. Cancer $\mathrm{J}$ 2013; 19(5):405-9.

26. Singh A, Singh RS, Sarma P, Batra G, Joshi R, Kaur H et al. A Comprehensive Review of Animal Models for Coronaviruses: SARS-CoV-2, SARS-CoV, and MERS-CoV. Virol Sin 2020; 35(3):290-304.

27. Belli S, Balbi B, Prince I, Cattaneo D, Masocco F, Zaccaria $S$ et al. Low physical functioning and impaired performance of activities of daily life in COVID-19 patients who survived hospitalisation. Eur Respir J 2020; 56(4). 
28. Woo MS, Malsy J, Pöttgen J, Seddiq Zai S, Ufer F, Hadjilaou A et al. Frequent neurocognitive deficits after recovery from mild COVID-19. Brain Commun 2020; 2(2):fcaa205.

\section{Figures}

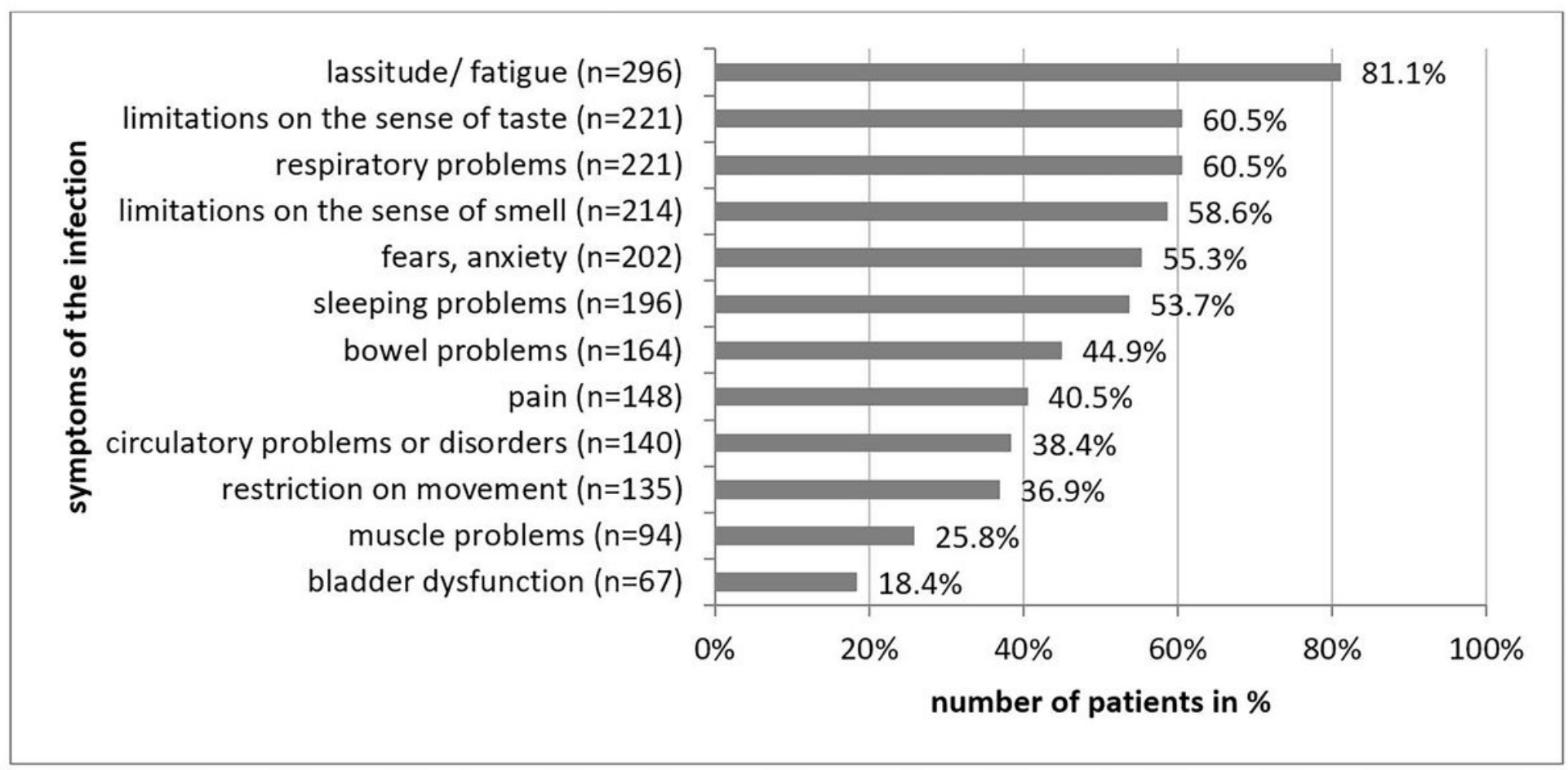

having shortness of breath during physical exertion $(n=255)$ carrying out daily routine $(n=245)$

을 handling stress $(n=228)$ providing care or support for others $(n=180)$ getting household tasks done $(n=180)$ relaxing, having pleasure $(n=176)$ looking after your health $(n=171)$ having intimate relationships $(n=155)$ interacting with people $(n=146)$ getting where you want to go $(n=117)$ using hands and fingers $(n=102)$ using public transportation( $n=93)$ using private transportation $(n=89)$

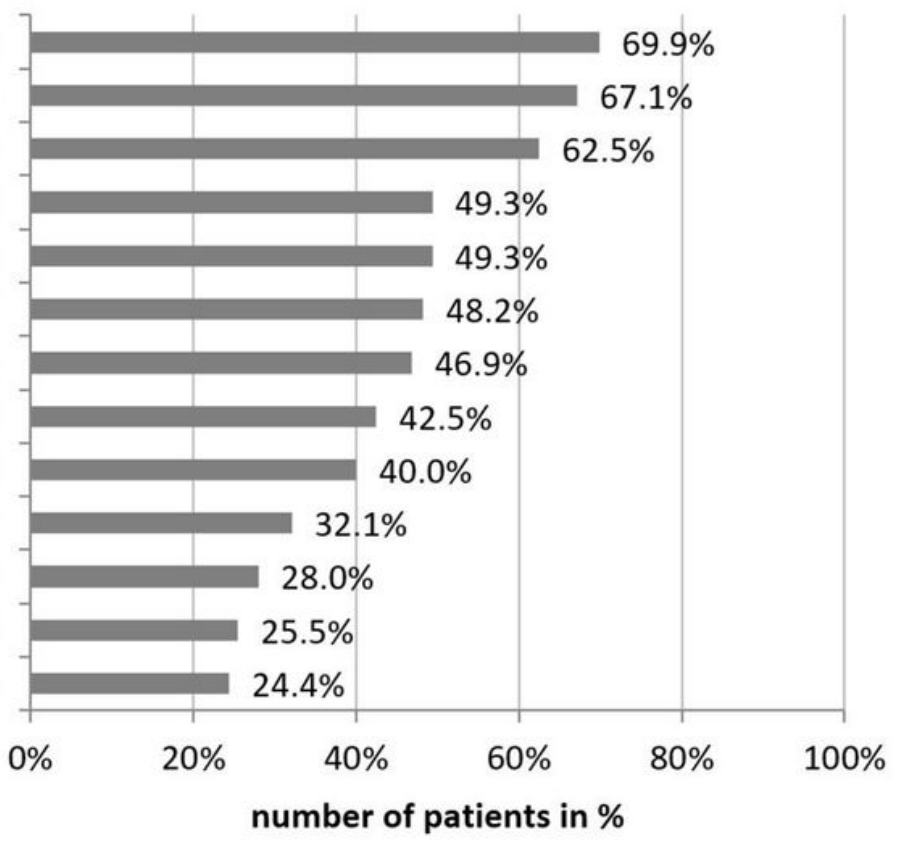

Figure 1

a: Symptoms early after infection. b: Problems in activity and participation during the infection phase. 


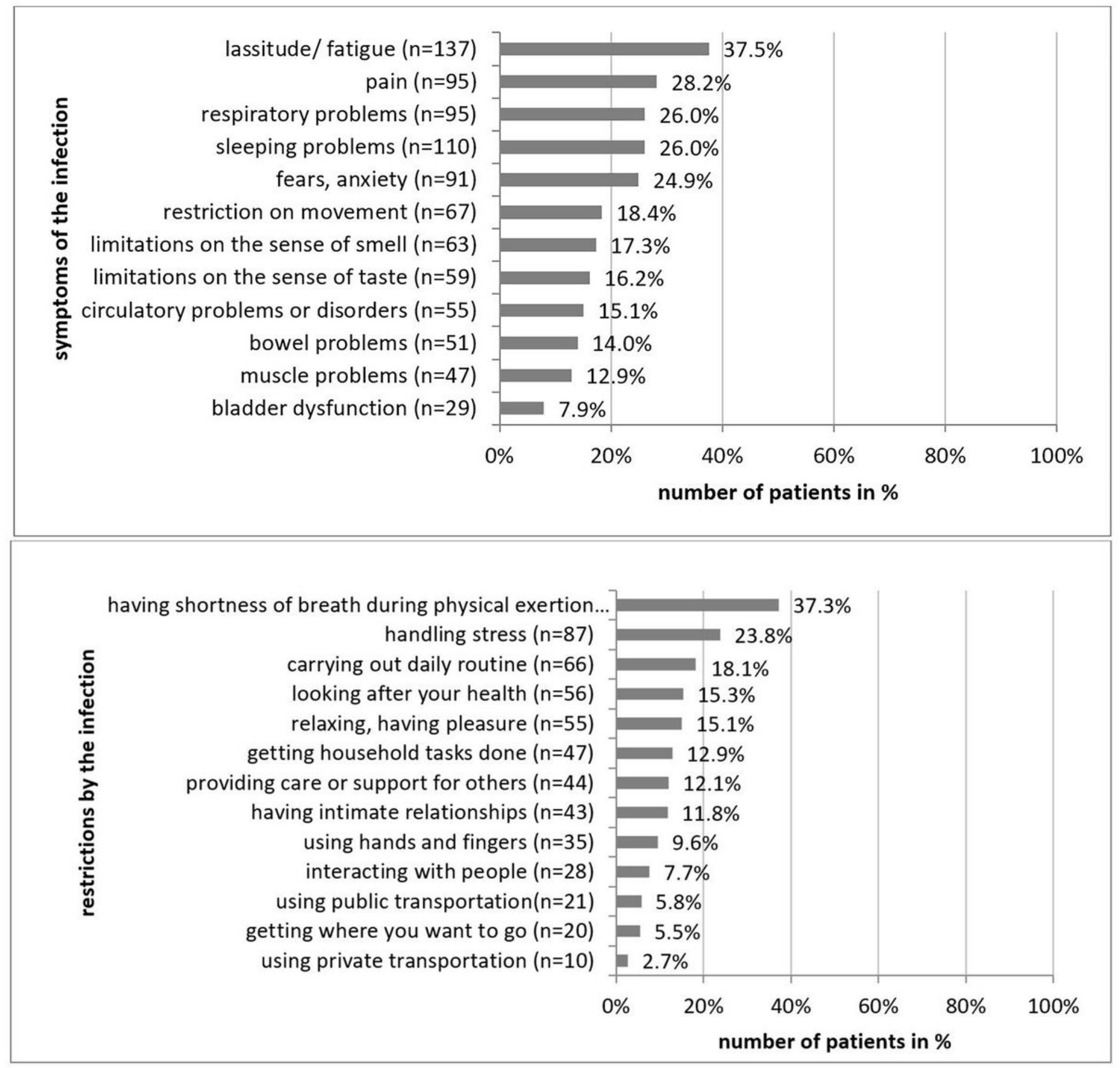

Figure 2

a: Long-term Symptoms 3 months after infection. b: Problems in activity and participation 3 months after infection. 


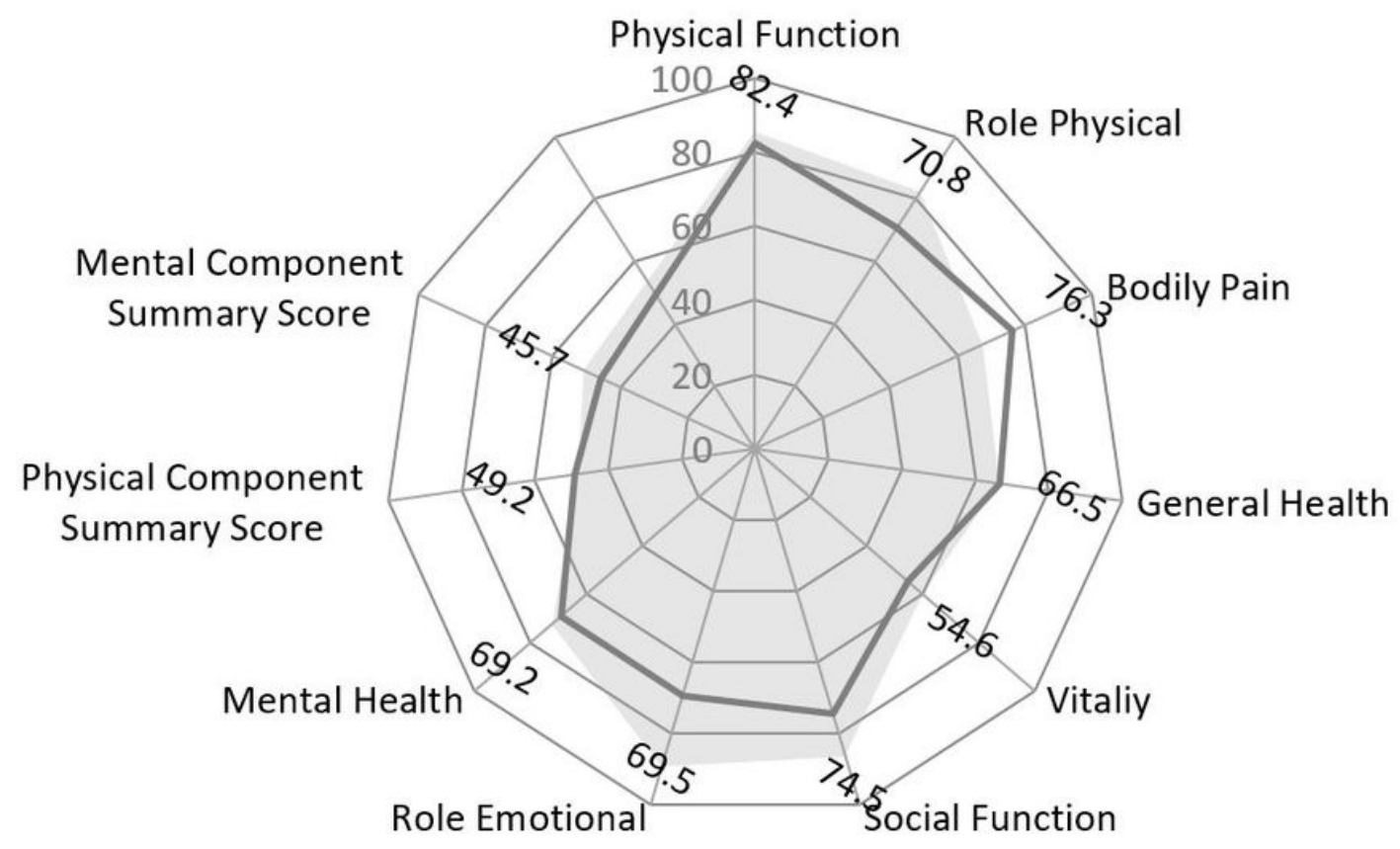

German Norm Data $\longrightarrow$ Sars-CoV-2

\section{Figure 3}

Results of SF-36, entire group $(n=365)$ 